\title{
Oestrogen plus progestin reduced risk of fracture in postmenopausal women
}

Cauley JA, Robbins J, Chen Z, et al. Effects of estrogen plus progestin on risk of fracture and bone mineral density: the Women's Health Initiative randomized trial. JAMA 2003;290:1729-38.

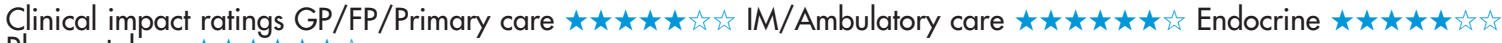

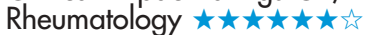

In postmenopausal women, does oestrogen plus progestin reduce the risk of fracture?

\section{METHODS}

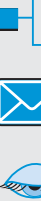

Design: randomised placebo controlled trial.

Allocation: $\left\{\right.$ allocation concealed $\left.{ }^{*}\right\}$

Blinding: blinded \{clinicians, participants, data collectors,

outcome assessors, and monitoring committee $\}$ †. $^{*}$

Follow up period: mean 5.6 years.

Setting: $\{40$ US clinical centres. $\} \dagger$

ofo Participants: 16608 women who were 50-79 years of age (mean age 63 y) and had an intact uterus. \{Exclusion criteria included probable survival of $<3$ years, cancer in the past 10 years, and low haematocrit or platelet counts. \}

D Intervention: a single table of either conjugated equine oestrogen, $0.625 \mathrm{mg} /$ day and medroxyprogesterone acetate, $2.5 \mathrm{mg} /$ day $(\mathrm{n}=8506)$, or placebo $(\mathrm{n}=8102)$.

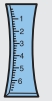

Outcomes: fracture (except fracture of the ribs, chest or sternum skull or face, fingers, toes, and cervical vertebrae). A global index assessed the benefits and risks of treatment by incorporating other disease outcomes (coronary heart disease; invasive breast, endometrial, or colorectal cancer; stroke; pulmonary embolism; hip fracture; and death from other causes).

Follow up: $94 \%$

*See glossary.

† Writing Group for the Women's Health Initiative Investigators. JAMA 2002;288:321-33.

\section{MAIN RESULTS}

Analysis was by intention to treat. Fewer women in the hormone therapy group than in the placebo group had a fracture (table). The effect for total fracture risk remained constant across different subgroups. When treatment effects on other important outcomes were included in a global model, hormone therapy had no net benefit, even in women with high risk of fracture.

\section{CONCLUSIONS}

In postmenopausal women, oestrogen plus progestin reduced the risk of fracture. In a global model assessing treatment effects on all outcomes, hormone therapy had no net benefit.

Abstract and commentary also appear in ACP Journal Club.

For correspondence: Dr J A Cauley, University of Pittsburgh, Pittsburgh, USA. jcauley@pitt.edu

Sources of funding: National Heart, Lung and Blood Institute and WyethAyerst Research.
Commentary

he study by Cauley et al provides final analysis of fracture endpoints previously reported in the Women's Health Initiative (WHI) trial. ${ }^{1}$ The authors, using a global index, confirmed there was no net benefit of oestrogen and progestin therapy even in women at high risk of fracture. However, the global index did not include such factors as the risk of dementia and the increase of gynaecological diagnostic procedures because of vaginal bleeding. The risk of probable dementia increased 2 fold in older women allocated to the oestrogen and progestin therapy and probably resulted from the increase in vascular dementia in the WHI Memory Study. ${ }^{2}$ In addition, the number of women requiring diagnostic biopsies increased more than 5 fold among those allocated to combined hormones. ${ }^{3}$

Of interest is the finding that oestrogen plus progestin reduced the risk of hip fractures only in women who reported a baseline calcium intake of $>1200 \mathrm{mg} /$ day. However, vitamin D intake was not reported.

These studies will assist women and their practitioners in making informed choices. Hormone therapy is no longer generally recommended preventive therapy, but in postmenopausal women with substantial vasomotor symptoms, hormone replacement may be a short term option primarily to treat symptoms and secondarily to decrease the risk of fractures. However, other therapies, such as bisphosphonates and selective receptor modulators, should be considered first line therapy for preventing and treating osteoporosis. ${ }^{4}$

Alexandra Papaioannou, MD McMaster University

Hamilton, Ontario, Canada

1 Rossouw JE, Anderson GL, Prentice RL, et al. Risks and benefits of estrogen plus progestin in healthy postmenopausal women: principal results from the Women's Health Initiative randomized controlled trial. JAMA 2002;288:321-33.

2 Shumaker SA, Legault C, Rapp SR, et al. Estrogen plus progestin and the incidence of dementia and mild cognitive impairment in postmenopausal women: the Women's Health Initiative Memory Study: a randomized controlled trial. JAMA 2003;289:2651-62.

3 Anderson $G L$, Judd $H L$, Kaunitz AM, et al. Effects of estrogen plus progestin on gynecologic cancers and associated diagnostic procedures: the Women's Health Initiative randomized trial. JAMA 2003;290:1739-48.

4 Cranney A, Guyatt G, Griffith L, et al. Meta-analyses of therapies for postmenopausal osteoporosis. IX: Summary of meta-analyses of therapies for postmenopausal osteoporosis. Endocr Rev 2002;23:570-8.

Oestrogen plus progestin $(\mathrm{O}+\mathrm{P}) v$ placebo in postmenopausal women at mean 5.6 years*

\begin{tabular}{|c|c|c|c|}
\hline Outcomes & $\begin{array}{l}\mathrm{O}+\mathrm{P} v \\
\text { placebo }\end{array}$ & $\operatorname{RRR}(95 \% \mathrm{Cl})$ & NNT (Cl) \\
\hline $\begin{array}{l}\text { Any fracture } \\
\text { Hip fracture }\end{array}$ & $\begin{array}{l}8.6 \% \vee 11 \% \\
0.6 \% \vee 0.9 \%\end{array}$ & $\begin{array}{l}23 \%(16 \text { to } 30) \\
33 \%(4.0 \text { to } 53)\end{array}$ & $\begin{array}{l}40(31 \text { to } 56) \\
338(210 \text { to } 2787)\end{array}$ \\
\hline & \multicolumn{3}{|c|}{ Hazard ratio $(\mathrm{Cl})$} \\
\hline $\begin{array}{l}\text { Lower arm or } \\
\text { wrist fracture } \\
\text { Vertebral } \\
\text { fracture }\end{array}$ & \multicolumn{3}{|c|}{$0.65(0.46$ to 0.92$)$} \\
\hline
\end{tabular}

*Abbreviations defined in glossary; RRR, NNT, and Cl calculated from data in article using Cox proportional hazards model. 